\title{
Evaluation of the antipsychotic medication review process at four long-term facilities in Alberta
}

This article was published in the following Dove Press journal:

Journal of Multidisciplinary Healthcare

4 October 2016

Number of times this article has been viewed

\author{
Arden Birney' \\ Paola Charland' \\ Mollie Cole ${ }^{2}$ \\ Mubashir Aslam Arain' \\ 'Workforce Research \& Evaluation, \\ ${ }^{2}$ Seniors Health Strategic Clinical \\ Network, Alberta Health Services, \\ Calgary, AB, Canada
}

Correspondence: Arden Birney Workforce Research \& Evaluation, Alberta Health Services, I030I Southport Lane SW, Calgary, AB T2W IS7, Canada

Tel + I 4039430185

Fax +I 4039432875

Email arden.birney@ahs.ca
Purpose: The goal of this evaluation was to understand how four long-term care (LTC) facilities in Alberta have implemented medication reviews for the Appropriate Use of Antipsychotics (AUA) initiative. We aimed to determine how interprofessional (IP) collaboration was incorporated in the antipsychotic medication reviews and how the reviews had been sustained. Methods: Four LTC facilities in Alberta participated in this evaluation. We conducted semistructured interviews with 18 facility staff and observed one antipsychotic medication review at each facility. We analyzed data according to the following key components that we identified as relevant to the antipsychotic medication reviews: the structure of the reviews, IP interactions between the staff members, and strategies for sustaining the reviews.

Results: The duration of antipsychotic medication reviews ranged from 1 to 1.5 hours. The number of professions in attendance ranged from 3 to 9 ; a pharmacist led the review at two sites, while a registered nurse led the review at one site and a nurse practitioner at the remaining site. The number of residents discussed during the review ranged from 6 to 20. The process at some facilities was highly IP, demonstrating each of the six IP competencies. Other facilities conducted the review in a less IP manner due to challenges of physician involvement and staff workload, particularly of health care aides. Facilities that had an nurse practitioner on site were more efficient with the process of implementing recommendations resulting from the medication reviews.

Conclusion: The LTC facilities were successful in implementing the medication review process and the process seemed to be sustainable. A few challenges were observed in the implementation process at two facilities. IP practice moved forward the goals of the AUA initiative to reduce the inappropriate use of antipsychotics.

Keywords: interprofessional, antipsychotic, senior, medication review, evaluation

\section{Introduction}

The Canadian Foundation for Healthcare Improvement estimates that one in three long-term care (LTC) residents take antipsychotic medications without proper clinical indications. They also note substantial variation in rates of antipsychotic use between LTC facilities, potentially indicating inappropriate use of antipsychotics. ${ }^{1}$ Recent studies have raised concern over adverse effects associated with long-term use of antipsychotics. Antipsychotic use among patients with dementia has been associated with increased risk of stroke, mortality, falls, and pneumonia. ${ }^{2}$ Researchers have also found a significant increase in long-term mortality and a significant decline in cognitive function for patients who receive antipsychotics compared to placebos. ${ }^{3,4}$ Additionally, recent research from Ontario found that new prescriptions of antipsychotics were 
associated with a $52 \%$ increased risk of serious falls and a $50 \%$ increased risk of fractures. ${ }^{5}$

In Alberta, the Seniors Health Strategic Clinical Network (SH SCN) noted a high prevalence $(26.8 \%)$ of antipsychotic use in the absence of psychotic and related conditions in 2011/2012. ${ }^{6}$ Alberta Health Services implemented a provincial quality improvement project with the goal of supporting LTC teams to ensure the appropriate use of antipsychotics (AUA) among seniors with dementia. The project was led by the SH SCN and the Addiction and Mental Health SCN, whose mandate includes spread of best practices within the province. The key performance measure was the Resident Assessment Instrument 2.0 Quality Indicator for the AUA. ${ }^{7}$ LTC teams were invited to attend a series of learning workshops. The workshops focused on building awareness of adverse effects associated with long-term use of antipsychotics and creating a desire to change. A webbased tool kit of resources was created to provide teams with strategies to explore nonpharmacological interventions as alternatives to antipsychotics. ${ }^{8}$ The Alberta Guideline on the Appropriate Use of Antipsychotic Medications and accompanying resources direct staff on the assessment and management of behaviors related to cognitive impairment. ${ }^{8}$ One of the main components of the Alberta Guideline on the Appropriate Use of Antipsychotic Medications was the implementation of an antipsychotic medication review process at LTC facilities.

\section{Why are medication reviews important in LTC?}

Seniors tend to have multiple comorbidities and take more medications than any other age group, which puts them at increased risk of medication-related adverse effects, such as unplanned hospital admissions. ${ }^{9,10}$ This risk highlights the need for conducting regular medication reviews to avoid adverse effects from medication. A medication review is a collaborative service provided by health care professionals to detect and prevent medication-related problems. ${ }^{11}$ Besides optimizing the use of medications, medication reviews also improve the quality, safety, and appropriate use of medications. ${ }^{9,11}$ Roberts et al ${ }^{12}$ conducted a randomized controlled trial evaluating the impact of medication reviews and staff education on care quality and medication use. Overall medication use decreased by $15 \%$ in the intervention group. The average number of antipsychotics administered per resident was also reduced in the intervention group. ${ }^{12}$
The Alberta Continuing Care Health Service Standards require monthly medication reviews for those who receive medications as a chemical or a pharmacological restraint. ${ }^{13}$ While a suggested strategy for implementing the medication reviews was shared with LTC teams, each site was encouraged to implement the reviews in a way that worked within the site context. LTC teams were asked to track the number of residents reviewed and the impact of dose reductions or discontinuation of antipsychotics on residents' behavior.

\section{What is the role of interprofessional collaboration (IPC)?}

The Canadian Interprofessional Health Collaborative developed a framework to guide interprofessional (IP) education and collaborative practice in various contexts. ${ }^{14}$ IPC is a "partnership between a team of health providers and a client in a participatory and coordinated approach to shared decision-making around health and social issues". ${ }^{14}$ IPC comprises six competency domains: 1) IP communication, 2) patient-/client-/family-/community-centered care, 3) role clarification, 4) team functioning, 5) collaborative leadership, and 6) IP conflict resolution. ${ }^{14}$ Evidence shows that IPC improves patient care delivery including increased access to health care, improved outcomes for people with chronic disease, less conflict among staff, better use of resources, easier recruitment of staff, and lower rates of staff turnover. ${ }^{15-17}$ According to the AUA guidelines, the antipsychotic medication reviews should be conducted interprofessionally by involving various team members from all shifts. This will ensure that the medication review comprehensively identifies reasons for antipsychotics use, risks vs benefits, side effects, and any behavior changes..$^{13}$ A recent study that followed up with facilities that introduced multidisciplinary medication reviews 3 years earlier found a decrease of $14 \%$ in antipsychotic prescriptions as well as a $23 \%$ decrease in antipsychotic prescriptions for residents without documented psychotic symptoms. ${ }^{18}$ One hundred and seventy LTC facilities throughout Alberta have implemented the AUA guidelines, resulting in the lowest antipsychotics use in Alberta in 2015 (18.1\%) as compared to other Canadian provinces..$^{19}$ The goal of this study was to understand how four LTC facilities in Alberta have implemented medication reviews for the AUA initiative. We aimed to determine how IPC was incorporated in the antipsychotic medication reviews and how the reviews have been sustained. We developed a checklist to capture structured observations in our study and also to use as an audit tool in the future. 


\section{Methods}

From September 2015 to April 2016, we conducted a qualitative study evaluating the IP antipsychotic medication review process at four LTC facilities in Alberta. This was an exploratory study. We wanted to explore different models of antipsychotic medication reviews and demonstrate the feasibility of each model. We purposively selected four LTC facilities where we had anecdotal evidence that the antipsychotic medication review processes were established and showed some reduction in the inappropriate use of antipsychotics. The SH SCN facilitated recruitment and participation of four LTC facilities. One facility was privately operated, while the other three facilities were operated by public organizations. Three facilities were located in urban settings and one in a rural area. The number of beds in the facilities ranged from 50 to 221 LTC beds.

\section{Interviews}

We developed an interview guide through collaboration with the SH SCN and using the IPC framework. The interview guide included questions pertaining to the process of medication review, team performance under the six IPC competency domains, and the perceived impact of medication review on the AUA.

We conducted semistructured interviews with staff at the selected LTC facilities. Semistructured interviews provide richer and in-depth data in comparison to structured interviews. ${ }^{20}$ Semistructured interviews are conducted in a way that the researcher starts a topic by posing a question, with deviation possible to make the interview more meaningful, thus giving an opportunity for participants to express their views freely. ${ }^{21}$ We conducted all interviews in person. The sampling was planned to achieve diversity in terms of the professional group. Ultimately, participants from varied professional groups participated: registered nurse (RN), licensed practical nurse (LPNs), health care aides (HCAs), pharmacists, and facility managers/directors. Although, the majority of interviews were conducted individually, some group interviews were conducted to accommodate the facilities staff schedule.

All interviews were audio recorded to aid our analysis. Notes were also taken.

\section{Antipsychotic medication review checklist}

We revised an existing document from the AUA tool kit, "Suggested Steps for Developing an Antipsychotic Medication Review Process", to develop an "Interprofessional Antipsychotic Medication Review Checklist for LTC facilities" (Figure S1). The goal was to provide the checklist to all LTC facilities in Alberta to be used as a standard tool to monitor and audit antipsychotic medication reviews at their facility. It was anticipated that the checklist would help staff track the quality of the antipsychotic medication review process and ensure the reviews are conducted interprofessionally. The checklist consisted of some items to be addressed before reviews, such as scheduling and organizing of the review, and other questions to be addressed during the review. The questions covered all six IP competency domains according to the Interprofessional Competency Framework. ${ }^{14}$ The checklist also included two Likert scale questions to rate the medication review process. For the face validity of the checklist, we obtained feedback from the staff who participated in the interviews.

\section{Observations}

We observed one antipsychotic medication review at each of the four selected LTC facilities. We conducted structured observations using the Interprofessional Antipsychotic Medication Review Checklist. We looked for the way the meetings were structured, which professions attended the review, who led the review, and collaborative interactions between team members. We compared our observations among the selected facilities to understand how the antipsychotic medication review was working at different facilities.

\section{Analysis}

We analyzed data according to the following key components that we identified as relevant to the antipsychotic medication reviews: the structure of the reviews, IP interactions between the staff members, and strategies for sustaining the reviews. The coding was carried out by the research team. Data were coded by hand using thematic analysis to identify recurring themes.

We obtained informed consent for the interviews and for observing the medication review process. We also wanted to ensure anonymity of participants in the findings. For example, we combined quotes from the best practice lead, care manager, and director under "Manager" to avoid linking them to individual responses.

This was considered a quality improvement project and did not require approval by an ethics review board. Data collection, analysis, and storage complied with the organization's confidentiality and health information policies (Freedom of Information and Protection of Privacy Act). 


\section{Results Observations}

We observed one antipsychotic medication review at each of the four LTC facilities. Table 1 provides a summary of staff present, review lead, duration of review, and number of residents discussed. The number of providers in attendance ranged from 3 to 9 . The duration of the review was 1 hour at three facilities and 1.5 hours at the fourth facility. The number of residents discussed ranged from 6 to 20 .

The overall purpose of the antipsychotic medication reviews was to reduce the inappropriate use of antipsychotics among residents. This was accomplished by reducing either the dose of an antipsychotic or the number of antipsychotic medications a resident is taking.

There were variations in the way LTC facilities have carried out antipsychotic medication reviews. We observed that the pharmacist was the lead at two facilities, while the RN was the lead at another facility. The fourth facility had an NP as their lead. The process of scheduling and organizing the review also varied from facility to facility. Most facilities scheduled the reviews to occur on a monthly basis, unless there was specific indication to hold them more frequently. The process at some facilities was highly IP demonstrating each of the six IP competencies as identified in the CIHC framework. Other facilities were missing some of the IP competencies due to some challenges of physician involvement and staff workload, particularly of HCAs. Facilities that had an NP on site were more efficient with the process of implementing recommendations resulting from the medication reviews. In the absence of a prescriber such as a physician or an NP, the review teams were able to only give recommendations and were not able to make changes in prescriptions.

\section{Interview findings}

We interviewed 18 participants from the four selected LTC facilities: five HCAs, three RNs, three LPNs, four pharmacists, one best practice lead, one care manager, and one facility director.

\section{Interprofessional competency domains \\ Role clarity}

Participants were clear about their role and the role of others during the review. Staff took on tasks that aligned with their role. At all facilities, the pharmacist produced a list of residents taking antipsychotics for review and provided feedback on medication dosage. The role of the RN was to obtain feedback from staff and communicate any changes in antipsychotic medication to staff. If present at the review, the HCAs and LPNs were primarily responsible for providing feedback on the day-to-day behaviors of the residents. The

Table I Observations of the antipsychotic medication reviews at four LTC facilities

\begin{tabular}{|c|c|c|c|c|c|}
\hline Facility & $\begin{array}{l}\text { Providers in } \\
\text { attendance }\end{array}$ & Review lead & $\begin{array}{l}\text { Approximate } \\
\text { duration of review }\end{array}$ & $\begin{array}{l}\text { Number of } \\
\text { residents discussed }\end{array}$ & $\begin{array}{l}\text { Staff shifts involved } \\
\text { (day/night/evening) }\end{array}$ \\
\hline Facility A & $\begin{array}{l}\text { RN team lead } \\
\text { Pharmacist } \\
\text { Care manager } \\
\text { LPN } \\
\text { HCA }\end{array}$ & $\mathrm{RN}$ team lead & I hour & 20 & $\begin{array}{l}\text { Day: RN team lead, pharmacist, care } \\
\text { manager, LPN, HCA } \\
\text { Evening: None } \\
\text { Night: None }\end{array}$ \\
\hline Facility B & $\begin{array}{l}\text { NP } \\
\text { LPN } \\
\text { RN } \\
\text { HCA } \\
\text { Pharmacist } \\
\text { Social worker } \\
\text { Recreational therapist } \\
\text { Care manager } \\
\text { Director of care }\end{array}$ & $\mathrm{NP}$ & 1.5 hours & 12 & $\begin{array}{l}\text { Day: NP, RN, pharmacist, care manager, } \\
\text { LPN, HCA, social worker, recreational } \\
\text { therapist, and director of care } \\
\text { Evening: None } \\
\text { Night: None }\end{array}$ \\
\hline Facility C & $\begin{array}{l}\text { Pharmacist } \\
\text { Care manager } \\
\text { Best practice lead } \\
\text { LPN }\end{array}$ & Pharmacist & I hour & 6 & $\begin{array}{l}\text { Day: LPN, pharmacist, care manager, } \\
\text { and best practice lead } \\
\text { Evening: None } \\
\text { Night: None }\end{array}$ \\
\hline Facility D & $\begin{array}{l}\text { Pharmacist } \\
\text { RN } \\
\text { HCA }\end{array}$ & Pharmacist & I hour & $9 *$ & $\begin{array}{l}\text { Day: Pharmacist } \\
\text { Evening: RN } \\
\text { Night: } \mathrm{HCA}^{* *}\end{array}$ \\
\hline
\end{tabular}

Notes: *Observations only occurred for the review of house 5 , which had the most residents on antipsychotics. We were unable to observe the review at the other four houses. Therefore, the number of residents discussed is likely higher. **HCA worked at both day and night shifts in house 5.

Abbreviations: LTC, long-term care; RN, registered nurse; LPN, licensed practical nurse; HCA, health care aides. 
manager was involved to assist in the review and to communicate information to families.

\section{Team functioning}

Participants reported on work dynamics and processes that enabled effective IPC in the medication review. Staff engaged in collaborative decision-making by participating and being respectful of other members' participation. Participants noted effective working relationships with other team members. Also, the participants were clear that different professional groups add another perspective to an issue.

It is interdisciplinary, we have people from various disciplines. We have health care aides, LPNs, RNs, management and physiotherapists. The medications we deal with affect every department in one way or another. Each discipline will see the patient in a different way than another. [LPN]

\section{Patient/family-centered care}

Participants described several ways in which families were invited to provide input into medication management. Antipsychotic medications are regularly discussed at family care conferences. Another strategy was sharing information with families about the need for antipsychotics and obtaining consent for any changes in these prescriptions. Participants also reported that the staff obtains feedback from families on resident behaviors to decide whether a medication change was useful for the resident. Participants noted that families are sometimes unclear about the need for antipsychotics for the residents.

\section{Collaborative leadership}

While there was a clear lead at each review, interview participants noted collaborative decision-making. Having a discussion, brainstorming and effective use of evidence were all methods used to reach a decision. Staff relied on each other's expertise to reach decisions.

The rationale has to be very clear, based on the documentation and the facts, not what people feel. We do not use authority to make decisions, we are all equal. Decisions must be based on facts and documentation. [Manager]

\section{Interprofessional communication}

Participants mentioned that two components of the review showed IP communication. First, the teams were using various methods to communicate changes in antipsychotic medication to other staff, in particular physicians. At three facilities, staff must communicate changes to physicians for prescription changes. Participants at one facility reported that they had clear ways to communicate changes to physicians through writing in the physician's binder, the resident chart, and by phoning them. Interview participants at the two other facilities stated that the process to communicate changes to physicians was inconsistent, noting that they would often make notes in the resident chart, and sometimes follow-up with a telephone call. At the fourth facility, an NP participates in the review and is able to change prescriptions.

The second component of IP communication included the methods used to obtain feedback from staff who did not attend the review. All participants noted the importance of getting feedback from various professions as they all have different roles in resident care. At several facilities, staff who were unable to attend the review (ie, night shifts) provided feedback during shift change, through 24-hour report notes and behavior mapping. However, some participants also noted that the staff-to-staff communication processes can be improved.

We do not have a process for communicating to other staff from other shifts who cannot attend the meeting - we would like it to be better. At the beginning of the [AUA] initiative we had boards that we updated to keep staff aware, but we did not think it was very useful so we stopped doing it and are looking for another solution. [Manager]

\section{Interprofessional conflict resolution}

Participants at several facilities described the use of discussion to resolve conflicts. The importance of documentation and facts were noted as key to resolving disagreements.

People will always have different views, but we are all professional, it is not personal. Everyone is here with good intentions for the resident. It is not about winning an argument, but doing what is right for the resident. We solve our conflicts with facts. We always record how and why we get to a decision, we always have a paper trail to justify our actions. [LPN]

\section{Perceived impact of the AUA initiative Improved staff knowledge}

Participants at all facilities felt that staff were more aware of the side effects of antipsychotics and had more knowledge on how to redirect challenging behaviors. Participants also acknowledged that staff demonstrated more creativity when managing residents' behaviors without using antipsychotics; eg, staff have used music, games, and puzzles to redirect residents' attention.

They were forced in a sense to become more creative and they have become very creative. I am just very impressed with what they do. Instead of giving the resident a drug to sedate them so that they are calm, they think of ways to distract 
them or how to interact with them so that the behavior will be calmer without drugs. [Pharmacist]

\section{Increased staff participation}

Participants noted more involvement in reducing inappropriate use of antipsychotics by various staff groups. For instance, active involvement of the HCAs at some facilities.

Before the HCA was not involved, now the HCA is involved and can talk with the rest of the HCAs. Before the HCAs did not have much knowledge about antipsychotic use, and now we are all educated. [HCA]

Participants at one facility felt that there is increased participation from all staff groups (eg, managers, physicians, and nurses), whereas previous medication reviews were conducted mainly by the pharmacist.

\section{Quality of life for the residents}

While most participants noted a decrease in the number of residents on antipsychotics, they agreed that numbers do not tell the whole story. Rather, resident quality of life was the real indication for success. Participants indicated that residents were more alert and interactive than before with their antipsychotic medications. Participants at one facility specifically noted a reduced risk of falls, as residents had more agility and experienced less dizziness.

There has been quality of life improvement. It will bring down the costs in terms of medication as well. There are people who are admitted who do not need the medication. Once you remove the medication the residents are active and engaging. The focus should be on quality of life, not numbers. The benefit to a human being is bigger than any cost or number. [RN]

\section{Challenges}

Physician involvement

Participants at several facilities indicated that while physician involvement would be good, it was unlikely to happen. Participants at some facilities noted a good communication process with physicians; others noted challenges or inconsistencies in communicating recommended changes to physicians. For instance, staff at one facility would leave notes in the resident charts, but sometimes these were missed by physicians. Participants noted that the reduction of antipsychotics may not be a priority for all physicians, and that some physicians do not always support recommendations to reduce antipsychotics.

\section{Staff availability and resources}

Participants reported that the need for staff might increase as residents become more involved in different activities instead of being sedated.

As we reduce the antipsychotics, the resident becomes active and starts wandering around so they need more attention so we need more staff. The staff will need more hours as the residents become more active, they are not just zombies anymore. [LPN]

Another staffing issue resulted from the time required to participate in the review process. Having staff participate in a review is a challenge as facilities have limited resources to replace front-line staff.

\section{Scheduling antipsychotic medication reviews}

Participants encountered some challenges in scheduling the reviews to include all staff. While staff often rotate shifts, the medication reviews cannot be scheduled at night to accommodate night nursing staff. Many staff also work part-time and are at the facility for a few days of the week, eg, pharmacist. Staff also need to ensure that there is adequate coverage for front-line operations during the review.

\section{Discussion}

Our study showed that IP medication reviews were successfully implemented in most LTC sites and proved beneficial to improving resident quality of care and health outcomes. The successful implementation of the IP medication review process was dependent on the active participation of all staff on the health care team that provided day-to-day care to residents. More specifically, IP practice proved to be beneficial to moving forward the goals of the AUA policy in reducing the inappropriate use of antipsychotics. These findings are supported by the literature on IP practice and its association with improved quality of care and patient outcomes. ${ }^{22}$

Working interprofessionally was integral to the success of medication reviews. Staff demonstrated IP competencies in their efforts to move the AUA policy forward. For example, the medication review's success was dependent on each provider's expertise and knowledge of the residents and clarity on each other's role in the process. Collaborative leadership and role clarity were demonstrated by participating sites in a similar manner. Most often, the pharmacist would lend their expertise on reducing the antipsychotic and note recommendations in the residents' chart, nursing staff would put through orders received from the physician or an NP, HCAs and nursing observed behaviors, and all staff got to know 
residents better to understand their behavior triggers. Collaborative leadership and communication were demonstrated through shared decision-making and seeking feedback from all staff about residents' behaviors and thoughts on reducing their antipsychotics. Furthermore, the reviews improved communication among staff and allowed for staff that was not usually approached for feedback to have a voice. Efforts made by staff to collaborate closely were indicative of good team functioning. Resident-centered care also improved through the increased attentiveness of staff. Rather than relying on antipsychotics to manage behavior, staff became creative in finding ways to distract and redirect behaviors using alternatives such as music, games, puzzles, and conversation. Overall, staff were pleased with the improvements they saw in residents who had their antipsychotics reduced and were eager to see more successes related to the AUA. Staff indicated that residents appeared to be experiencing a better quality of life, had improved awareness, increased engagement, and happiness.

Sustainability of the AUA policy via IP medication reviews was made evident by facilities in their efforts to customize processes. The facilities amended their process to ensure that the reviews continued and remained effective. Some sites scheduled the medication reviews in advance for a year. Other sites scheduled the review depending on staff's availability each month. At one site where it was more difficult for staff to leave the floor to attend the medication review, they modified the process so that the medication review went to staff instead. For example, staff attending the medication review went to each area of the facility with the list of residents on antipsychotics and discussed the antipsychotic use for those residents with staff on the floor. This is in line with the literature on program sustainability. Literature on achieving program sustainability supports changing processes as a means of enhancing the adoption of program components into regular practice. ${ }^{23}$ Conceptualizing sustainability needs to have an underpinning of learning and adapting processes over time. ${ }^{24}$ A barrier to implanting recommendations from the medication reviews included the lack of physician involvement. Physicians were not involved in the medication reviews at any of the sites in our study; however, our findings indicate that it would facilitate the AUA policy and benefit quality of care if physicians participated or had a prescriber participate in medication review team. Sites that did not have an NP relied heavily on physicians to review and approve recommendations from the medication review. They had to wait until the physician visited the facility before learning if the recommendation would be approved. Even then, physicians did not always support recommendations from the medication review team. Barriers to the implementation of recommendations arising from medication reviews are well documented in the literature and are commonly experienced when physician involvement in the medication review is little or nonexistent. ${ }^{25,26}$

Study sites that had an NP as part of their team did not experience the challenge of implementing recommendations made at the medication review. In fact, their process was more efficient because the NP participated in the medication review and could order changes to resident's medications immediately. Historically, the position of medical director of LTC facilities was created as a way to improve physician involvement in $\mathrm{LTC}^{27}$ A medical director could help to spearhead policies and initiatives such as the AUA policy with LTC physicians to improve outcomes. That being said, other avenues should also be explored.

A potential solution to the barrier of heavy reliance on physicians as the prescriber in LTC may be to explore the possibility of using other providers as prescribers. As discussed previously, an NP as part of the IP team had positive impacts on the adoption of the AUA policy. This is in line with the literature that shows an NP in LTC can help to reduce polypharmacy rates among residents. ${ }^{28}$ Most facilities involved in our study had a pharmacist who attended or led the medication review, so it could make sense for pharmacists to fill the role of prescriber. In the province of Alberta, this would require an expansion in pharmacist's scope of practice. ${ }^{29}$ Evidence from randomized trials shows an association with direct pharmacist involvement in patient care and positive health outcomes, supporting the expansion of pharmacist's scope of practice..$^{29}$ Changes to legislation to expand the scope of practice of pharmacists in Canada are in various stages of implementation. ${ }^{29-31}$ However, currently in Alberta, all activities related to expanding the prescribing authority of pharmacists have been implemented. ${ }^{30}$ This expanded scope includes the ability to initiate drug therapy and the ability to alter another prescriber's original/ existing/current prescription orders. ${ }^{30}$ In order to practice in this expanded scope of practice, pharmacists must complete additional training and certification and be approved by their regulatory body. ${ }^{30,31}$ Expanding the role of pharmacists in LTC could mitigate the challenges related to physicians being present to approve the medication review recommendations and, ultimately, facilitate the reduction of antipsychotics.

The findings from this exploratory study are limited by the small sample size as we only evaluated antipsychotic medication reviews at four LTC facilities. Future research should further explore the impact of IPC in medication reviews on antipsychotic use. 


\section{Conclusion}

Our findings showed that some facilities were successful in implementing the medication review process and also effectively demonstrated IP practice competencies with a few challenges. Other facilities demonstrated some challenges in engaging staff from different professions and from different shifts. Staff expressed satisfaction with the Interprofessional Antipsychotic Medication Review Checklist and looked forward to using it in future medication reviews.

Based on the evaluation, we make the following key recommendations to implement an antipsychotic medication review at a LTC facility:

- Identify a core antipsychotic medication review team with providers from diverse professional backgrounds. To ensure that the core review team is working interprofessionally: 1) clearly define roles and responsibilities in the antipsychotic medication review process and 2) build an IP communication strategy with them.

- Engage HCAs in medication reviews as they observe behavior changes in the residents and would feel valued in giving input.

- Include a prescriber on the core review team to change medication orders while the review is underway.

- Build an effective communication mechanism with the physician (when an NP or other prescriber is not an option) integral to the medication review process.

Overall, the antipsychotic medication reviews proved beneficial in improving resident quality of care and health outcomes. In addition, IP practice moved forward the goals of the AUA initiative to reduce the inappropriate use of antipsychotics.

\section{Acknowledgment}

We would like to thank the staff and managers from the long-term care facilities for generously contributing their time to this project.

\section{Disclosure}

The authors report no conflicts of interest in this work.

\section{References}

1. Canadian Foundation for Healthcare Improvement. Fact Sheet: Reducing Antipsychotic Medication Use in Long Term Care Collaborative. 2014. Available from: http://www.cfhi-fcass.ca/sf-docs/default-source/ work-with-us/fact-sheet-reducing-antipsychotic-medications-e. pdf?sfvrsn=18. Accessed February 1, 2016.

2. Mittal V, Kurup L, Williamson D, Muralee S, Tampi R. Risk of cerebrovascular adverse events and death in elderly patients with dementia when treated with antipsychotic medications: a literature review of evidence. Am J Alzheimers Dis Other Demen. 2011;26(1):10-28.
3. Ballard C, Hanney M, Theodoulos M, et al. The dementia antipsychotic withdrawal trial (DART-AD): long-term follow-up of a randomised placebo-controlled trial. Lancet Neurol. 2009;8(2):151-157.

4. Vigen C, Mack W, Keefe R, et al. Cognitive effects of atypical antipsychotic medications in patients with Alzheimer's disease: outcomes from CATIE-AD. Am J Psychiatry. 2011;168(8):831-839.

5. Fraser L, Liu K, Naylor K, et al. Falls and fractures with atypical antipsychotic medication use: a population-based cohort study. JAMA Intern Med. 2015;175(3):450-452.

6. Seniors Health Strategic Clinical Network. Physician Update on Appropriate Use of Antipsychotics (AUA) Project. 2015. Available from: http://www.albertahealthservices.ca/assets/about/scn/ahs-scn-srs-auaupdate-2015-07.pdf. Accessed January 28, 2016.

7. Alberta Health. RAI-MDS 2.0 Quality Indicator Interpretation Guide. 2015. Available from: http://www.health.alberta.ca/documents/ CC-CIHI-RAI-Guide-2015.pdf. Accessed June 3, 2016.

8. Seniors Health Strategic Clinical Network [webpage on the Internet]. Appropriate Use of Antipsychotics (AUA) Toolkit for Care Teams. Available from: http://www.albertahealthservices.ca/scns/auatoolkit. aspx. Accessed February 3, 2016.

9. Nishtala P, McLachlan A, Bell J, Chen T. Psychotropic prescribing in long-term care facilities: impact of medication reviews and educational interventions. Am J Geriatr Psychiatry. 2008;16(8):621-632.

10. Accreditation Canada, the Canadian Institute for Health Information, the Canadian Patient Safety Institute, and the Institute for Safe Medication Practices Canada. Medication Reconciliation in Canada: Raising the Bar-Progress to Date and the Course Ahead. Ottawa, ON: Accreditation Canada; 2012.

11. Blenkinsopp A, Bond C, Raynor D. Medication reviews. Br J Clin Pharmacol. 2011;74(4):573-580.

12. Roberts M, Stokes J, King M, et al. Outcomes of a randomized controlled trial of a clinical pharmacy intervention in 52 nursing homes. Br J Clin Pharmacol. 2001;51(3):257-265.

13. Seniors Health Strategic Clinical Network. Medication Review Requirements for Appropriate Use of Antipsychotics. 2014. Available from: http://www.albertahealthservices.ca/assets/about/scn//ahs-scn-srs-auamedication-review.pdf. Accessed January 28, 2016.

14. Canadian Interprofessional Health Collaborative. A National Interprofessional Competency Framework. 2010. Available from: http://www. cihc.ca/files/CIHC_IPCompetencies_Feb1210.pdf. Accessed February 2, 2016.

15. Canadian Health Services Research Foundation. Teamwork in Healthcare: Promoting Effective Teamwork in Healthcare in Canada. 2006. Available from: http://www.cfhi-fcass.ca/migrated/pdf/teamworksynthesis-report_e.pdf. Accessed February 4, 2016.

16. Canadian Health Services Research Foundation. CHSRF Synthesis: Interprofessional Collaboration and Quality Primary Healthcare. 2007. Available from: http://www.cfhi-fcass.ca/Migrated/PDF/ResearchReports/CommissionedResearch/SynthesisReport_E_rev4_FINAL.pdf. Accessed February 4, 2016.

17. Interprofessional Care Steering Committee. Interprofessional Care: $A$ Blueprint for Action in Ontario. 2007. Available from: http://solr.bccampus.ca:8001/bcc/file/74c545d1-b0ff-086a-e3c1-132118b9b485/1/ ipc\%20blueprint\%20final.pdf. Accessed February 4, 2016.

18. Schmidt K, Fastbom J. Quality of drug use in Swedish nursing homes: a follow-up study. Clin Drug Investig. 2000;20(6):433-446.

19. Seniors Health Strategic Clinical Network \& Addiction and Mental Health Strategic Clinical Network. November AUA Project Bulletin. 2015. Available from: http://www.albertahealthservices.ca/assets/about/ scn/ahs-scn-srs-bulletin-2015-11.pdf. Accessed January 28, 2016.

20. Smith J. Semi-structured interviewing and qualitative data analysis. In: Smith J, Harre R, Van Langenhave L, editors. Rethinking Methods in Psychology. London: Sage; 1995:9-26.

21. Britten N. Qualitative interviews in medical research. Br Med J. 1995;311(6999):251-253.

22. Zwarenstein M, Goldman J, Reeves S. Interprofessional collaboration: effects of practice-based interventions on professional practice and healthcare outcomes (review). The Cochrane Library. 2009;4:1-29. 
23. Hanson H, Salmoni A. Stakeholders' perceptions of programme sustainability: findings from a community-based fall prevention programme. Public Health. 2011;125(8):525-532.

24. Hanson H, Salmoni A, Volpe R. Defining program sustainability: differing views of stakeholders. Can J Public Health. 2009;100(4): 304-309.

25. Chen T. Exploring the elements of interprofessional collaboration between pharmacists and physicians in medication review. Pharm World Sci. 2007;29(6):574-576.

26. Kwint H, Bermingham L, Faber A, Bouvy M. The relationship between the extent of collaboration of general practitioners and pharmacists and the implementation of recommendations arising from medication review. Drugs Aging. 2013;30(2):91-102.
27. Rahim-Jamal S, Quail P, Bhaloo T. Developing a national role description for medical directors in long-term care: survey-based approach. Can Fam Physician. 2010;56(1):e30-e35.

28. Klassen K, Lamont L, Krishnan P. Setting a new standard of care in nursing homes. Can Nurse. 2009;105(9):24-30.

29. Tannenbaum $C$, Tsuyuki T. The expanding scope of pharmacists' practice: implications for physicians. Can Med Assoc J. 2013;185(14):1228-1232.

30. Canadian Pharmacists Association [webpage on the Internet]. Pharmacists' Scope of Practice in Canada; 2016. Available from: http:// www.pharmacists.ca/pharmacy-in-canada/scope-of-practice-canada. Accessed February 2, 2016.

31. Yuksel N, Eberhart G, Bungard T. Prescribing by pharmacists in Alberta. Am J Health Syst Pharm. 2008;65(22):2126-2132. 


\section{Supplementary material}

Figure SI Interprofessional Antipsychotic Medication Review Checklist

\section{Interprofessional Antipsychotic Medication Review Checklist}

\section{Instructions:}

Date:

Please place a $\$ in the "Yes" OR "No" space for the listed questions. Note any next steps or comments.

Staff members present: $\square$ HCA $\quad \square$ LPN $\quad \square$ RN $\quad \square$ Pharmacist $\quad \square$ Physician $\quad \square$ PT $\quad \square$ OT $\quad \square$ Others:

Has the team:

$\square$ Scheduled regular medication reviews

$\square$ Obtained a list from pharmacy to identify residents on regularly scheduled and PRN antipsychotics

$\square$ Identified who will be on the medication review team and who will lead the process

$\square$ Tracked behaviors to identify periods of calm and triggers for responsive behaviors

$\square$ Reviewed Medication Administration Records and progress notes for PRN antipsychotic use; look for effectiveness, patterns, and rationale

$\square$ Discussed possible underlying reasons for the behaviors with the family and care team members. Identify more effective care strategies and integrate those into the care plan

$\square$ Determined who will be responsible for documenting in physician communication book, charts, or electronic progress notes

\begin{tabular}{|c|c|c|c|}
\hline During the review & Yes & No & Next steps/comments \\
\hline \multicolumn{4}{|l|}{ Are staff from more than one shift included (ie, days and evenings)? } \\
\hline \multicolumn{4}{|l|}{$\begin{array}{l}\text { Has the team collected input from those who are unable to attend, } \\
\text { prior to the meeting? }\end{array}$} \\
\hline \multicolumn{4}{|l|}{ Do team members feel comfortable expressing their opinion? } \\
\hline \multicolumn{4}{|l|}{$\begin{array}{l}\text { Is there a clear lead for the medication review process? } \\
\text { What profession are they? }\end{array}$} \\
\hline \multicolumn{4}{|l|}{$\begin{array}{l}\text { Are team members knowledgeable about their roles and the } \\
\text { roles of other disciplines in attendance? }\end{array}$} \\
\hline \multicolumn{4}{|l|}{$\begin{array}{l}\text { Are all antipsychotic medication prescriptions supported } \\
\text { with a clinical indication? }\end{array}$} \\
\hline \multicolumn{4}{|l|}{$\begin{array}{l}\text { Have the medications for ALL residents who are transferring } \\
\text { from one level of service to another been reviewed? } \\
\text { (Note any adjustments of antipsychotic use that need to be made) }\end{array}$} \\
\hline \multicolumn{3}{|l|}{ Do any of the following scenarios apply to residents in care? } & \\
\hline \multicolumn{3}{|l|}{$\begin{array}{l}\text { Discontinue unused PRNs where there is no scheduled } \\
\text { antipsychotics }\end{array}$} & \\
\hline \multicolumn{3}{|l|}{$\begin{array}{l}\text { - Taper/discontinue antipsychotic medication prescribed for } \\
\text { behaviors not likely to respond }\end{array}$} & \\
\hline \multicolumn{3}{|l|}{ - Taper/discontinue medication for residents with no behaviors } & \\
\hline \multicolumn{3}{|l|}{$\begin{array}{l}\text { - Taper/discontinue medication for agitation and aggression } \\
\text { that has stabilized }\end{array}$} & \\
\hline \multicolumn{3}{|l|}{$\begin{array}{l}\text { - Taper/discontinue antipsychotic(s) on new admission within } \\
\text { 4-6 weeks }\end{array}$} & \\
\hline $\begin{array}{l}\text { - Discuss who provides alternative approach to address } \\
\text { resident behavior after discontinuing antipsychotics }\end{array}$ & & & \\
\hline
\end{tabular}




\begin{tabular}{|c|c|c|c|}
\hline During the review & Yes & No & Next steps/comments \\
\hline \multicolumn{4}{|l|}{$\begin{array}{l}\text { Are disagreements among team members constructively } \\
\text { addressed, while acknowledging differing perspectives? }\end{array}$} \\
\hline \multicolumn{4}{|l|}{$\begin{array}{l}\text { Do all staff present at the medication review participate in } \\
\text { decision-making? }\end{array}$} \\
\hline \multicolumn{4}{|l|}{ Are there any barriers to communication? If so, what? } \\
\hline \multicolumn{4}{|l|}{ Are decisions clear? } \\
\hline \multicolumn{4}{|l|}{ Are next steps clear? } \\
\hline \multicolumn{4}{|l|}{$\begin{array}{l}\text { Are all team members satisfied with the process of the } \\
\text { medication review? }\end{array}$} \\
\hline \multicolumn{4}{|l|}{$\begin{array}{l}\text { Is someone clearly responsible to communicate all changes and } \\
\text { recommendations to patients, families, and all other shifts? How? }\end{array}$} \\
\hline $\begin{array}{l}\text { How would you rate this month's medication review? } \\
\text { (Please circulate appropriate box) }\end{array}$ & \multicolumn{3}{|c|}{$\square^{\prime}$ Very Poor $\square^{2}$ Not good $\square^{3}$ Average $\square^{4}$ Good $\square^{5}$ Excellent } \\
\hline $\begin{array}{l}\text { Do you think this month's medication review is according to } \\
\text { the AUA guidelines? } \\
\text { (Please circulate appropriate box) }\end{array}$ & \multicolumn{3}{|c|}{$\begin{array}{l}\square^{\prime} \text { Strongly disagree } \square^{2} \text { Disagree } \square^{3} \text { Neither agree nor disagree } \square^{4} \text { Agree } \\
\square^{5} \text { Strongly agree }\end{array}$} \\
\hline
\end{tabular}

Abbreviations: LPN, licensed practical nurse; HCA, health care aide; AUA, Appropriate Use of Antipsychotics; RN, registered nurse; PT, physical therapist; OT, occupational therapist.

The Journal of Multidisciplinary Healthcare is an international, peerreviewed open-access journal that aims to represent and publish research in healthcare areas delivered by practitioners of different disciplines. This includes studies and reviews conducted by multidisciplinary teams as well as research which evaluates the results or conduct of such teams or health

\section{Dovepress}

care processes in general. The journal covers a very wide range of areas and welcomes submissions from practitioners at all levels, from all over the world. The manuscript management system is completely online and includes a very quick and fair peer-review system. Visit http://www.dovepress.com/ testimonials.php to read real quotes from published authors. 